\title{
O CURRÍCULO DE LIBRAS: UM ESTUDO EXPLORATÓRIO EM UMA INSTITUIÇÃO FEDERAL DE ENSINO, NO MUNICÍPIO DE SÃO ROQUE, ESTADO DE SÃO PAULO
}

\author{
Lizandra de Cassia Souto Proença ${ }^{1}$ \\ Alequexandre Galvez de Andrade ${ }^{2}$ \\ Valter Zotto de Andrade ${ }^{3}$
}

\begin{abstract}
Resumo: A noção de inclusão está ligada ao direito de igualdade. O presente estudo trata-se de uma pesquisa sobre o currículo do ensino de Libras no Instituto Federal de São Paulo, no município de São Roque, estado de São Paulo, e tem como objetivo identificar e comparar os conteúdos de Libras aplicados aos cursos de Ensino Médio profissionalizante e Superior. A metodologia utilizada foi à pesquisa bibliográfica e exploratória. Foram analisados os projetos pedagógicos dos sete cursos ofertados pela instituição em 2015. Os resultados indicam que três cursos não possuem o componente curricular de libras e quatro cursos possuem o mesmo conteúdo programático e bibliografia, independentemente se pertencem ao ensino médio ou superior. O curso de Licenciatura em Biologia voltado para formação de professores possui uma carga horária inferior ao ensino médio profissionalizando, sendo respectivamente de 31,6 e 63,3.
\end{abstract}

Palavras-chave: Libras; Currículo; Formação do Professor.

\footnotetext{
1 Pós-graduada em Libras/Faculdade Educacional da Lapa - FAEL, Brasil. E-mail: lizandraproenca@yahoo.com.br.

2 Docente do curso de Administração/Instituto Federal de São Paulo, Campus São Roque, Brasil. Email:aleq.galvez@ifsp.edu.br.

3 Docente do curso de Pós-graduação em Libras/Faculdade Educacional da Lapa - FAEL, Brasil. E-mail: pl.saopaulo1.sp@fael.edu.br.
} 